\title{
Cross-Sectional Distributions of Mechanical Properties of Fine Cu-Sn Alloy Wire Manufactured by Continuous Rotary Draw Bending
}

\author{
Junichiro Tokutomi ${ }^{1}$, Kenichi Hanazaki ${ }^{1}$, Nobuhiro Tsuji ${ }^{2}$ and Jun Yanagimoto ${ }^{3}$ \\ ${ }^{1}$ Yazaki Research and Technology Center, Yazaki Corporation, Shizuoka 410-1194, Japan \\ ${ }^{2}$ Graduate School of Engineering, Department of Material Science and Engineering, Kyoto University, Kyoto 606-8501, Japan \\ ${ }^{3}$ Institute of Industrial Science, The University of Tokyo, Tokyo 153-8505, Japan
}

\begin{abstract}
The changes in the mechanical properties on the inside and outside of the bend of $\mathrm{Cu}-0.3$ mass $\%$ Sn wire specimens deformed by rotary draw bending were clarified, and the correlation between the changes in the misorientation of substructures and in the mechanical properties was systematically investigated. The specimens were each divided into two parts, i.e., the inside and outside of the bend, and their mechanical properties and microstructure evolution were measured by performing tensile tests. From the results, it was found that the ultimate tensile strength and $0.1 \%$ proof stress on the inside of the bend decreased markedly and that the total elongation was improved upon rotary draw bending. Although the tensile strength on the inside of the bend decreased, the change in grain size was very small. If rotary draw bending is performed on a wire specimen, it is considered that the dislocations generated by the tensile stress field are relaxed by the reversed stress induced during such bending. [doi:10.2320/matertrans.MH201323]
\end{abstract}

(Received May 10, 2013; Accepted June 21, 2013; Published August 2, 2013)

Keywords: mechanical properties, ultrafine grain, microstructure, copper alloy, bending

\section{Introduction}

It has recently been shown that severe plastic deformation (SPD) processes are effective for manufacturing ultrafinegrain (UFG) microstructures with mean grain sizes of less than $1 \mu \mathrm{m}$, as reviewed by Azushima et al. ${ }^{1)}$ Various SPD processes, such as accumulative roll bonding (ARB), $\left.{ }^{2-5}\right)$ equal-channel angular processing (ECAP), ${ }^{6,7)}$ and highpressure torsion (HPT), ${ }^{8,9)}$ have been proposed for ultra grain refinement. These processes can be used to produce UFG bulk materials. On the other hand, deep wire drawing can also be used to produce a large cumulative strain in metallic materials. ${ }^{10)}$

Negroni et al. used copper and copper alloy as test materials for wire drawing and investigated the changes in various mechanical properties at a large strain with up to 99\% reduction in area. ${ }^{11)}$ Hanazaki et al. ${ }^{10)}$ clarified that wire drawing can be used as an SPD process and that the substructure of a wire specimen deformed by wire drawing consists of lamellae with dislocation substructures inside grains. Therefore, wire drawing is promising for fabricating high-strength and high-conductivity copper wires by a strengthening mechanism based on grain refinement. The above studies have shown that wire drawing can be applied to the practical mass production of copper wires. Although the mechanism of strength improvement in UFG materials fabricated by wire drawing has been gradually clarified, that of ductility improvement remains unclear.

In our previous studies, a continuous bending-drawing (CBD) method entailing wire drawing and draw bending was proposed to improve the ductility of a wire-drawn specimen. ${ }^{12,13)}$ Note that the tensile ductility of a wire-drawn specimen recovers after draw bending. Also, it was found that, during draw bending, the hardness of a wire-drawn specimen is lower than that of a specimen subjected to wire drawing, particularly on the inside of the bend. ${ }^{14)}$ However, the effect of the change in the microstructure of a wire-drawn specimen on the mechanical characteristics of a material subjected to draw bending has not yet been clarified. To clarify the relationship between the mechanical properties and microstructure of the CBD specimens, microstructures including dislocation substructures and texture should be investigated quantitatively. In this study, we separately investigated the changes in the mechanical properties on the inside and outside of a bend of a wire processed by CBD process to determine the cross-sectional distribution of the mechanical properties. Then, the relationship between the changes in the misorientation of substructures and in the mechanical properties is discussed.

\section{Experimental}

\subsection{CBD process and materials}

A dilute $\mathrm{Cu}-\mathrm{Sn}$ alloy was used in this investigation. Table 1 shows the chemical composition of the alloy. As shown in the table, the alloy contained only a small amount of $\mathrm{Sn}$ as the alloying element, so as not to reduce the electric conductivity of the wire. Figure 1 shows a schematic illustration of the CBD process used in this investigation. An initial rod of the $\mathrm{Cu}-\mathrm{Sn}$ alloy with a mean grain size of $10 \mu \mathrm{m}$ was prepared by grooved rolling followed by annealing, which completely eliminated residual strain. Before cold wire drawing, annealing at $673 \mathrm{~K}$ for $60 \mathrm{~min}$ in a nitrogen atmosphere was conducted to homogenize the solute and microstructure. Multipass wire drawing was carried out with lubrication at room temperature to achieve area reduction. The equivalent strain in wire drawing is defined as

Table 1 Chemical composition of $\mathrm{Cu}-0.3$ mass $\%$ Sn alloy (mass\%).

\begin{tabular}{cccccccc}
\hline & $\mathrm{O}$ & $\mathrm{As}$ & $\mathrm{S}$ & $\mathrm{Fe}$ & $\mathrm{P}$ & $\mathrm{Pb}$ & $\mathrm{Al}$ \\
\hline $\begin{array}{c}\mathrm{Cu}-0.3 \\
(\mathrm{mass} \%) \mathrm{Sn}\end{array}$ & 0.014 & $<0.001$ & 0.266 & $<0.001$ & 0.001 & $<0.001$ & Bal. \\
\hline
\end{tabular}




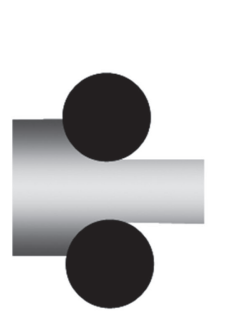

Rolling

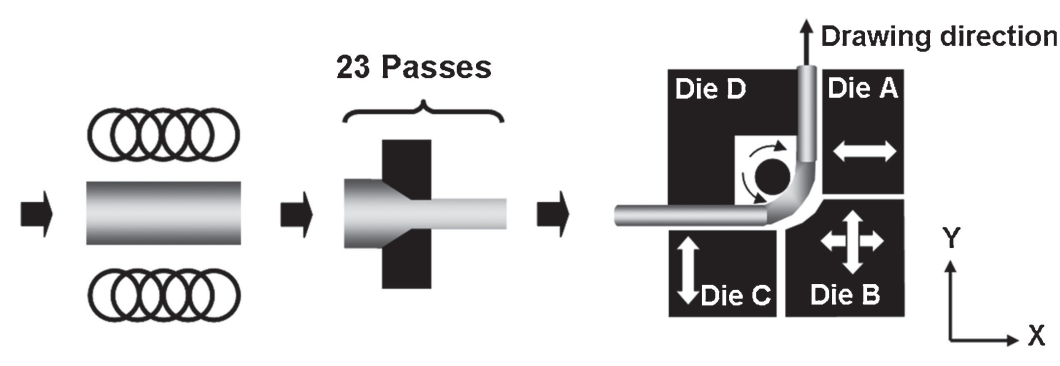

Annealing

Wire drawing

Draw bending

Fig. 1 Schematic diagram of sample setup for CBD process.

Table 2 Pass schedules, equivalent strains, and resultant wire diameters in wire drawing.

\begin{tabular}{lcccccccc}
\hline No. of passes & 0 & 1 & 2 & 3 & 4 & 5 & 6 & 7 \\
\hline Wire diameter, $d / \mathrm{mm}$ & 7.70 & 6.90 & 6.18 & 5.44 & 4.78 & 4.30 & 3.85 & 3.45 \\
Total reduction, $R(\%)$ & 0 & 19.7 & 35.58 & 50.09 & 61.46 & 68.81 & 75.00 & 79.92 \\
Equivalent strain, $\varepsilon^{\mathrm{WD}}$ & 0 & 0.2 & 0.4 & 0.7 & 1.0 & 1.2 & 1.4 & 1.6 \\
\hline No. of passes & 8 & 9 & 10 & 11 & 12 & 13 & 14 & 15 \\
\hline Wire diameter, $d / \mathrm{mm}$ & 3.20 & 2.60 & 2.31 & 1.81 & 1.43 & 1.13 & 0.89 & 0.74 \\
Total reduction, $R(\%)$ & 82.73 & 88.60 & 91.00 & 94.44 & 96.55 & 97.85 & 99.64 & 99.07 \\
Equivalent strain, $\varepsilon$ WD & 1.8 & 2.2 & 2.4 & 2.9 & 3.4 & 3.8 & 4.3 & 4.7 \\
\hline No. of passes & 16 & 17 & 18 & 19 & 20 & 21 & 22 & 0.21 \\
\hline Wire diameter, $d / \mathrm{mm}$ & 0.61 & 0.50 & 0.42 & 0.34 & 0.28 & 0.23 & & \\
Total reduction, $R(\%)$ & 99.37 & 99.57 & 99.71 & 99.80 & 99.86 & 99.90 & 99.92 & 7.2 \\
Equivalent strain, $\varepsilon$ & 5.1 & 5.4 & 5.8 & 6.2 & 6.6 & 7.0 & & \\
\hline
\end{tabular}

$$
\varepsilon^{\mathrm{WD}}=\ln \frac{S_{0}}{S_{n}},
$$

where $S_{0}$ and $S_{n}$ are the cross-sectional areas of the initial rod and the drawn rod after $n$ passes, respectively. Table 2 shows a summary of the pass schedules, equivalent strains, $\varepsilon^{\mathrm{WD}}$ and resultant wire diameters in the present wire drawing. The diameter of the initial rod was $7.7 \mathrm{~mm}$, and the smallest diameter achieved after 23 passes was $0.21 \mathrm{~mm}$; thus, the maximum total area reduction was $99.93 \%$, which corresponded to a total equivalent strain of 7.2.

Draw bending was performed to induce plastic deformation in the final step of the CBD process. In Fig. 1, the design and arrangement of the draw-bending die are shown, which are the same as those used in our previous study. ${ }^{12)}$ The shaft has a groove that fits the diameter of the wire to ensure the smooth flow of the wire during draw bending, eliminating tilting or twisting. The true bending strain $\varepsilon^{\text {bending }}$ was estimated using the equation ${ }^{14)}$

$$
\varepsilon^{\text {bending }}=\ln \left(1+\frac{d_{\mathrm{a}}}{R_{\mathrm{n}}}\right)\left(1+\frac{d_{\mathrm{b}}}{R_{\mathrm{n}}}\right),
$$

where $R_{\mathrm{n}}$ is the radius of curvature at the neutral plane of the wire specimen $\left(R_{\mathrm{n}}=0.84 \mathrm{~mm}\right)$, and $d_{\mathrm{a}}$ and $d_{\mathrm{b}}$ are the radii of the wire specimen after and before draw bending, respectively. The equivalent $\varepsilon^{\text {bending }}$ during draw bending was 0.23 , which was selected to obtain the optimum strength-ductility balance from the result of our previous study. ${ }^{12)}$ The drawbending conditions are shown in Table 3. The wire was drawn in the $Y$-direction at a relatively low speed of
Table 3 Draw bending conditions used in present study.

\begin{tabular}{lll}
\hline & $\begin{array}{l}\text { Die A and B } \\
\text { Die B and C }\end{array}$ & 0.30 \\
\cline { 2 - 3 } Distance between various dies [mm] & $\begin{array}{l}\text { Die A and D } \\
\text { Die C and D }\end{array}$ & 0.25 \\
\hline Velocity ratio & & $-1.0,1.0,3.0$ \\
\hline Drawing speed $[\mathrm{mm} / \mathrm{s}]$ & & 1.66 \\
\hline
\end{tabular}

$1.66 \mathrm{~mm} / \mathrm{s}$. One feature of the rotary draw-bending die is that the rotational direction and angular velocity of the shaft can be controlled. Note that, at an angular velocity of $11.12 \mathrm{rad} / \mathrm{s}$ and a drawing speed of $1.66 \mathrm{~mm} / \mathrm{s}$, the velocity ratio is 1.0 . Hence, when the velocity ratio exceeds 1.0 , the wire is driven by the rotating shaft.

\subsection{Evaluation method}

Figure 2 shows a schematic of the preparation of the dumbbell-type specimens used in the tensile test by mechanical polishing and electrochemical polishing. To obtain detailed mechanical properties of the CBD specimens, wire specimens were prepared by mechanical polishing and divided into two parts by the neutral plane of a bend (as shown in Figs. 2(a) and 2(b)). To remove the mechanical polishing layer and produce the shape of the simple dumbbell-type specimens, the electrochemical polishing was carried out in phosphoric acid aqueous solution (as shown in Fig. 2(c)). The thin wire specimens were subjected to electrochemical polishing at $1 \mathrm{~V}$ for $10 \mathrm{~s}$ by placing on 
(a)
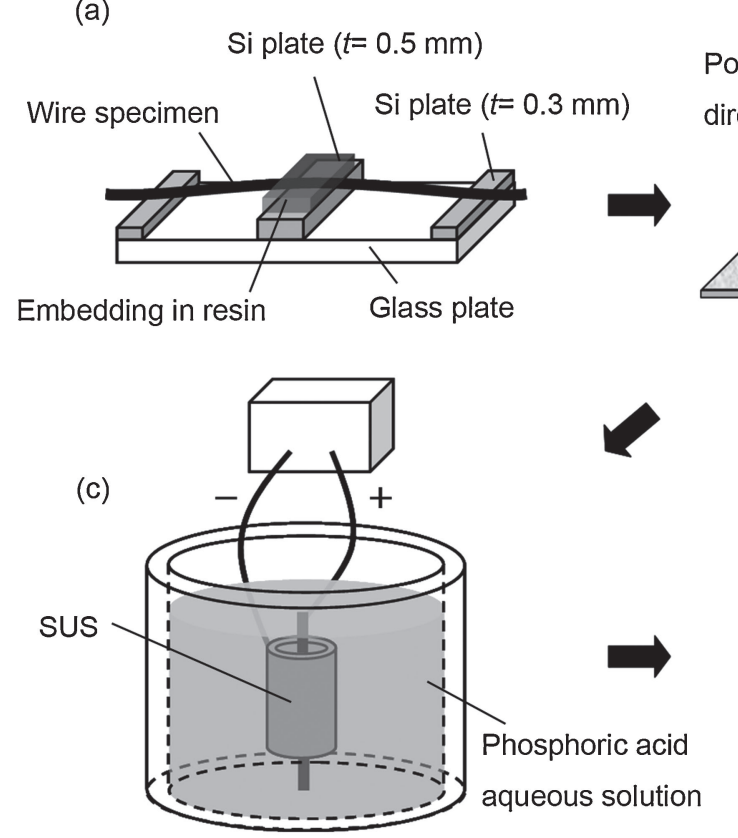

Electric voltage: $1 \mathrm{~V}$

Processing time: $10 \mathrm{sec}$

Temperature: $279 \mathrm{~K}$ (b)

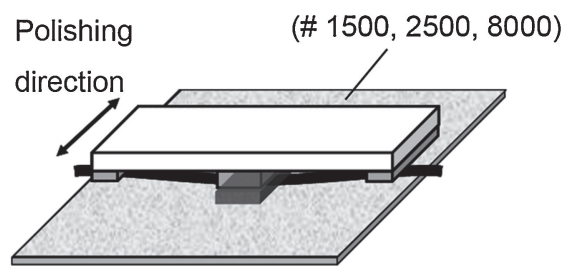

(d)

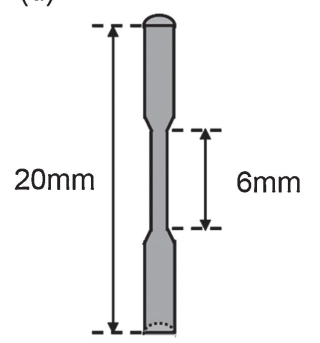

Fig. 2 Schematic diagram showing preparation of the specimens used the tensile test by mechanical polishing and electrochemical polishing.

SUS tube $(\phi=3.0 \mathrm{~mm}$ and $L=6.0 \mathrm{~mm})$ in the cathode. The simple dumbbell-type specimens were prepared from 20-mm-long straight wires and their mechanical properties were then measured. A tensile test was carried out on the specimens at a nominal strain rate of $3 \times 10^{-3} \mathrm{~s}^{-1}$ at room temperature after wire drawing and the $\mathrm{CBD}$ process. The strength of the wire specimens was measured using an Instron-type testing machine with cord and yarn grips, which prevented jaw breaks in the specimens. Wire elongation was measured using a video extensometer with two foam polystyrene spheres containing slits as markers. The initial gauge length was $4 \mathrm{~mm}$.

The cross sections and longitudinal sections of the wire specimens were subjected to ion beam polishing at $4.5 \mathrm{kV}$ for $8 \mathrm{~h}$ in an argon gas atmosphere. After that, the microstructural and crystallographic features of the wire specimens after wire drawing and the $\mathrm{CBD}$ process were determined by electron backscatter diffraction (EBSD) analysis using a field-emission-type scanning electron microscopy (FE-SEM) system operated at $25 \mathrm{kV}$ and equipped with a TSL orientation imaging microscopy system. The microstructures of the specimens subjected to wire drawing and the CBD process were measured using $15 \mu \mathrm{m} \times 15 \mu \mathrm{m}$ and $25 \mu \mathrm{m} \times$ $10 \mu \mathrm{m}$ mapping areas on the cross section and longitudinal section with a scan pitch of $0.1 \mathrm{~nm}$ to obtain reliable texture data, respectively.

Dislocation substructures in grains were observed by scanning transmission electron microscopy (STEM) at $200 \mathrm{kV}$. Thin foils with a thickness of approximately $0.08 \mu \mathrm{m}$ were prepared for STEM using a focused ion beam (FIB), and edge sections of the inside and outside of the bend perpendicular to the drawing direction were observed.

\section{Results}

\subsection{Mechanical properties}

Figure 3 shows the nominal stress-strain curves for wire specimens processed at various velocity ratios. The ultimate tensile strength (UTS) and $0.1 \%$ proof stress were approximately 750 and $530 \mathrm{MPa}$, respectively, which were the same for all the wire specimens subjected to the CBD process. The UTS and $0.1 \%$ proof stress of the CBD specimens were almost 40 and $150 \mathrm{MPa}$ lower than those of the wire-drawn specimen, respectively. The total elongation of the CBD specimen processed at a velocity ratio of 3.0 was $3.6 \%$. These mechanical properties were the same as those reported in our previous study. ${ }^{14)}$

Figure 4 shows the nominal stress-strain curves for the wire specimens separated into the (a) inside and (b) outside of the bend. The UTS and $0.1 \%$ proof stress on the inside of the bend of the CBD specimens were decreased by draw bending, reaching approximately 510 and $390 \mathrm{MPa}$ at velocity ratios of 1.0 and 3.0, respectively, which are about two-thirds of those of the wire drawn specimen. On the other hand, the UTS and $0.1 \%$ proof stress on the outside of the bend were only slightly decreased, reaching approximately 680 and $550 \mathrm{MPa}$, respectively. Regarding the decrease in $0.1 \%$ proof stress, it is considered that the additional shear strain layer ${ }^{15,16)}$ generated beneath the surface layer of the wire specimens is removed. When the UTS and $0.1 \%$ proof stress on the inside and outside of the bend of the CBD specimens were compared at various velocity ratios, it was concluded that the inside of the bend softened more markedly than the outside. The total elongation on the inside of the bend of the CBD specimens increased to $1.6 \%$ (velocity ratio 


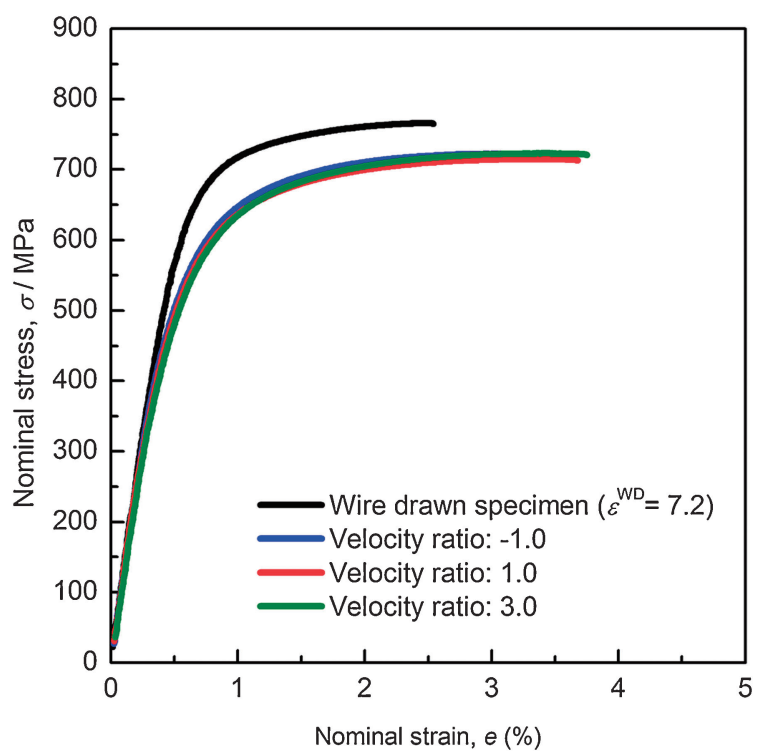

Fig. 3 Nominal stress-strain curves for $\mathrm{Cu}-0.3$ mass\% $\mathrm{Sn}$ alloy specimens processed at various velocity ratios.
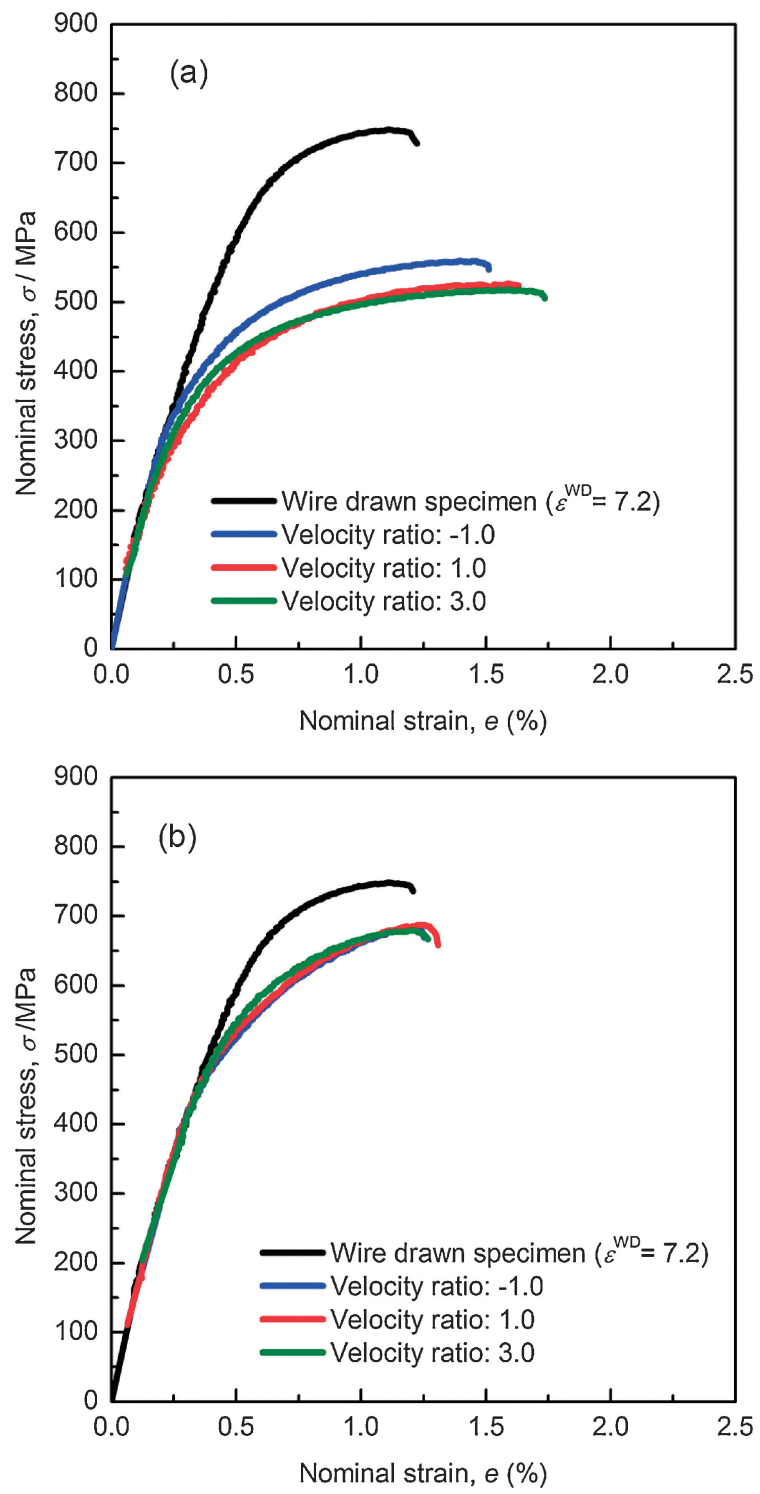

Fig. 4 Nominal stress-strain curves for wire specimens separated into (a) inside and (b) outside of bend.
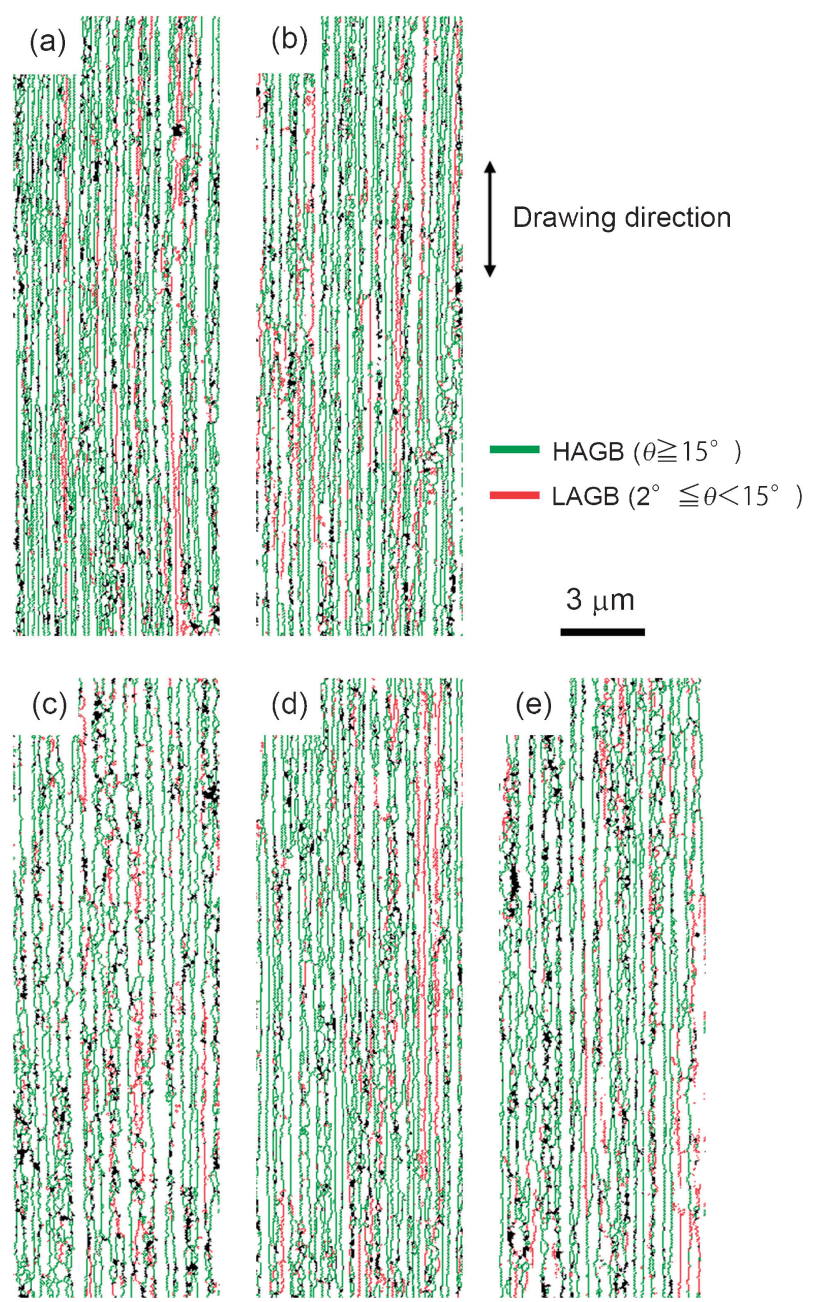

Fig. 5 Boundary maps of longitudinal section of a wire specimen at velocity ratio of 3.0. The images in (a) and (b) are of the edge and center of a wire-drawn specimen and those in (c), (d) and (e) are of the inside, center and outside of the bend of a CBD specimen, respectively.

of -1.0 ) and $1.8 \%$ (velocity ratio of 3.0 ), which were about 1.5 times greater than that of the wire-drawn specimen. The total elongation on the outside of the bend slightly increased, reaching approximately $1.3 \%$ at various velocity ratios.

\subsection{Macroscopic observation of metallographic struc- ture during CBD}

Figure 5 shows boundary maps of a wire-drawn specimen and a CBD specimen at the center and edge of each specimen on a longitudinal section. Boundaries with misorientation angles ranging from 2 to $15^{\circ}$ are considered to be low-angle grain boundaries (LAGBs), and those with misorientation angles larger than $15^{\circ}$ are considered to be high-angle boundaries (HAGBs); those with misorientation angles of less than $2^{\circ}$ are disregarded to eliminate the inaccuracy in the EBSD measurement and analysis. Grains were observed to be elongated parallel to the drawing direction in the wire-drawn specimen and CBD specimen. Hardly any grain refinement was observed on the inside and outside of the CBD specimen under this experimental condition, as shown Figs. 5(b) and 5(d).

Figure 6 shows inverse pole figure maps of the wire-drawn specimen and CBD specimens obtained at the center and 


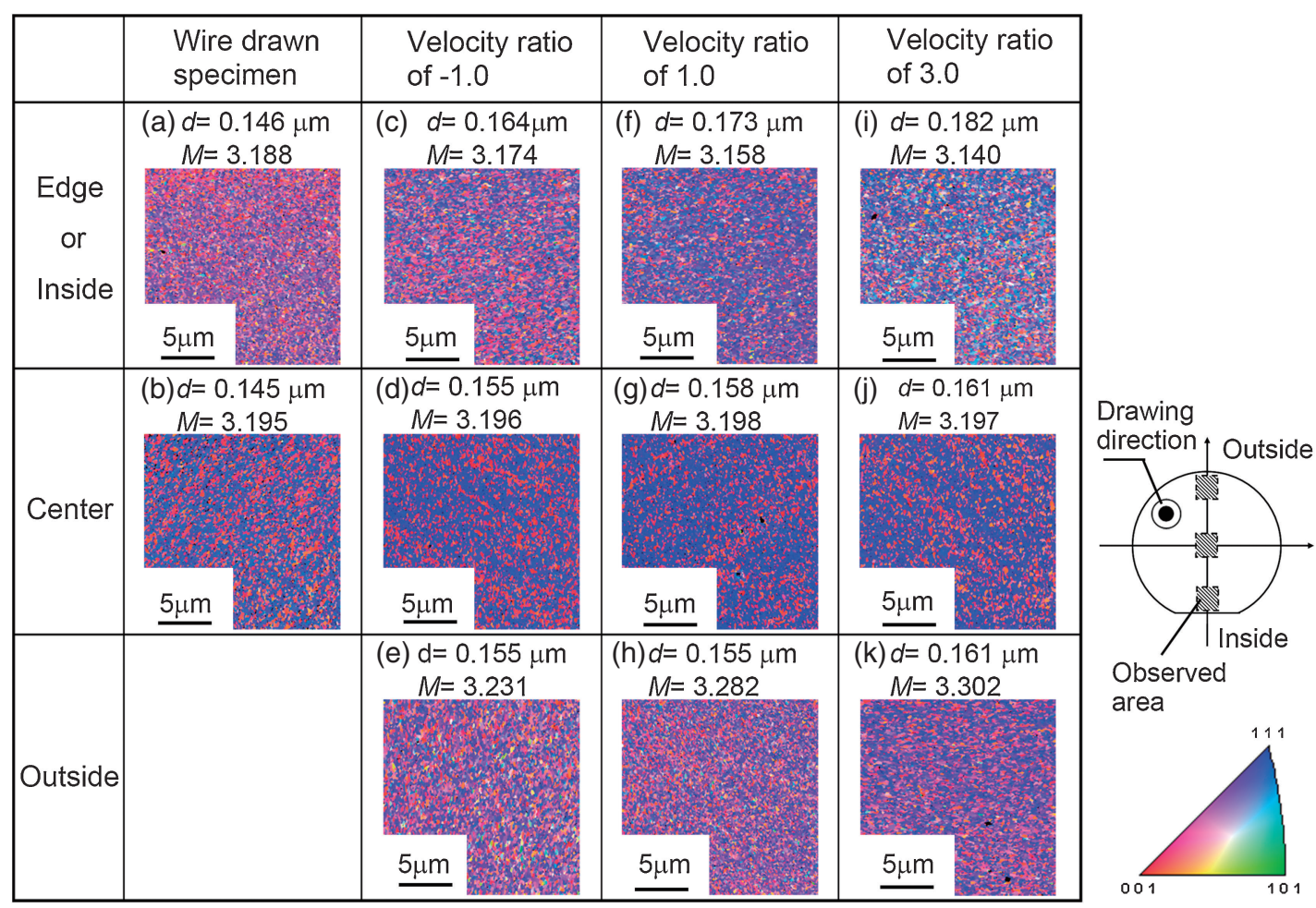

Fig. 6 Inverse pole figure maps of inside of bend at various velocity ratios. The images in (c), (d) and (e); (f), (g) and (h); and (i), (j) and (k) correspond to velocity ratios of $-1.0,1.0$ and 3.0, respectively. The images in (a) and (b) were obtained at the edge and center of the wire-drawn specimen, respectively. The images in (c), (f) and (i); (d), (g) and (j); and (e), (h) and (k) were obtained on the inside, at the center, and on the outside of the bend of CBD specimens, respectively.

edge of the specimens on the cross section. The wire-drawn specimen and CBD specimens exhibited a distinct texture composed of grains in the $\langle 001\rangle$ and $\langle 111\rangle$ directions at their center, which is a typical drawing texture component of f.c.c. metals. ${ }^{17,18)}$ The texture of grains in the $\langle 001\rangle$ and $\langle 111\rangle$ directions changed at the edge of the wire-drawn specimen. From this change at the edge of the wire drawn specimen, it was clarified that shear stress was induced by wire drawing. ${ }^{15,16)}$ On the other hand, the inside and outside of the bend were found to exhibit a larger change in texture at the edge of the CBD specimens than at the edge of the wiredrawn specimen, especially at a velocity ratio of 3.0. The texture at the edge of the CBD specimens was quantitatively evaluated using the Taylor factor. The Taylor factors on the inside of the bend of the CBD specimens were 3.174 and 3.140 at velocity ratios of -1.0 and 3.0 , respectively. Additionally, the Taylor factors on the outside of the bend of the CBD specimens were 3.231 and 3.302 at velocity ratios of -1.0 and 3.0, respectively. The Taylor factor had decreased on the inside of the bend of the CBD specimen even though it was subjected to draw bending. In particular, it can be considered that a peculiar change in the texture occurred on the inside of the bend when the rotating speed of the shaft was increased.

From boundary map of the same area as that shown in Fig. 6, the area of crystal grains was defined as the area enclosed by HAGBs, and the mean distance between HAGBs was defined as the mean grain size. The mean grain size of the wire drawn specimen measured in the cross-sectional area was $0.145 \mu \mathrm{m}$. On the inside of the bend of the specimens processed at various velocity ratios, the mean grain size ranged from 0.164 to $0.182 \mu \mathrm{m}$. The mean grain size increased with increasing rotational speed when the shaft rotated in the positive direction, i.e., in the drawing direction. On the outside of the bend, the grain size increased slightly, ranging from 0.155 to $0.162 \mu \mathrm{m}$. Such grain growth may be due to the rotation of the metallic crystal induced by the load stress during draw bending.

The changes in the number fraction of HAGBs on the inside and outside of the bend at various velocity ratios on the cross section are summarized in Fig. 7. The number fraction of HAGBs on the inside of the bend was less than that of the wire-drawn specimen, reaching a minimum of 0.727 at a velocity ratio of 3.0. However, the number fraction of HAGBs on the outside of the bend was higher than that of the wire-drawn specimen, reaching a maximum of 0.823 at a velocity ratio of 3.0. On the inside and outside of the CBD specimens, it can be considered that the change in the number fraction of HAGBs is affected by the load stress and strain during draw bending. The change in the metallographic structure is considered in section 4.2 on the basis of the continuum mechanics in the $\mathrm{CBD}$ process.

\subsection{Microstructure evaluation under STEM}

Micrographs of the wire specimens after wire drawing obtained by STEM on the cross section are shown in Fig. 8. The wire-drawn specimen [Fig. 8(a)] formed ultrafine grains with dislocation substructures because a large equivalent drawing strain of 7.2 was introduced by cold-wire drawing. When subsequent draw bending was performed on the wiredrawn specimen, it was observed that the CBD specimens had dislocation substructures inside their grains as shown in 


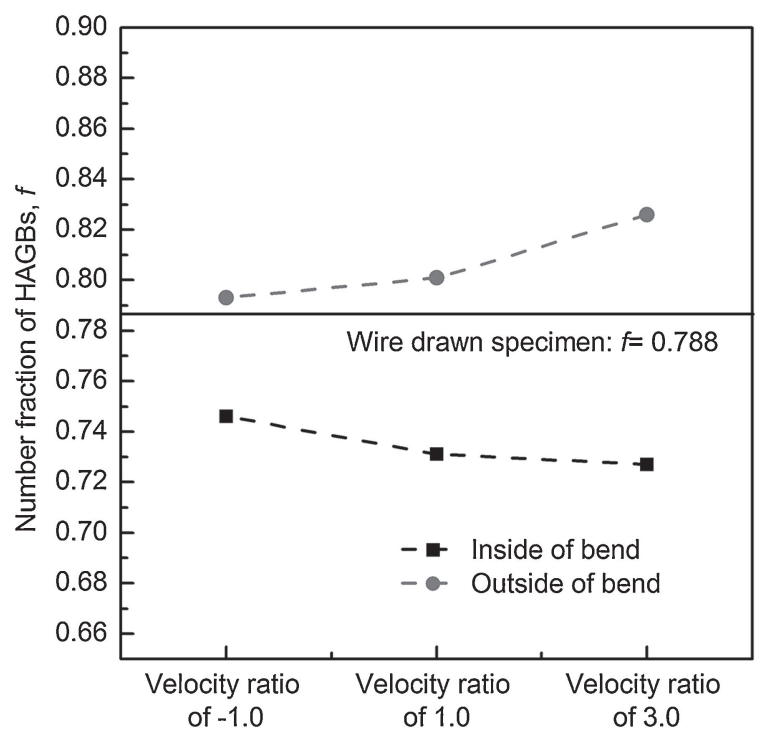

Fig. 7 Changes in the number fraction of HAGBs obtained from EBSD data at various angular velocities.

Figs. $8(\mathrm{~b})-8(\mathrm{~g})$. Under the same conditions, for example a velocity ratio of 1.0 , similar dislocation substructures were observed on the inside and outside of the bend. It was clarified by Wang et al. and Niewczas et al. that deformation twins of copper easily form during processing at an extremely low temperature of $150 \mathrm{~K}$ or less. ${ }^{19,20)}$ However, the CBD process in the present study was performed at room temperature, and the temperature of the $\mathrm{Cu}-\mathrm{Sn}$ wire increased during the CBD process. Therefore, no deformation twins were observed on the wire-drawn specimen and CBD specimens.

\section{Discussion}

\subsection{Changes in mechanical properties}

In this section, we discuss the cause of the changes in the mechanical properties on the inside and outside of the bend. Kamikawa et al. ${ }^{21)}$ reported that the strength mechanism of UFG metallic materials can be regarded as a combination of grain refinement and dislocation strengthening, and that the $0.1 \%$ proof stress is strongly affected by dislocation strengthening.

Figure 9 shows the relationships between the $0.1 \%$ proof stress and mean grain size on the inside and outside of the bend. The short dashed line in Fig. 9 shows the Hall-Petch equation for $\mathrm{Cu}-\mathrm{Sn}$ alloy wire specimens, and the relationship between the large grains of the $\mathrm{Cu}-\mathrm{Sn}$ alloy wire specimens and the Hall-Petch equation shows good agreement. ${ }^{22)}$ However, the $0.1 \%$ proof stresses on the inside and outside of the bend do not correspond to the dashed line in Fig. 9. This is considered to be due to dislocation strengthening, as shown by Kamikawa et al. ${ }^{21)}$ Moreover, the $0.1 \%$ proof stress of the CBD specimens, particularly on the inside of the bend, is markedly lower than that of the wire-drawn specimen, although the change in grain size is very small. This marked decrease might be related to the change in the dislocation structure of the grains. If draw bending is performed on a wire-drawn specimen, it can be
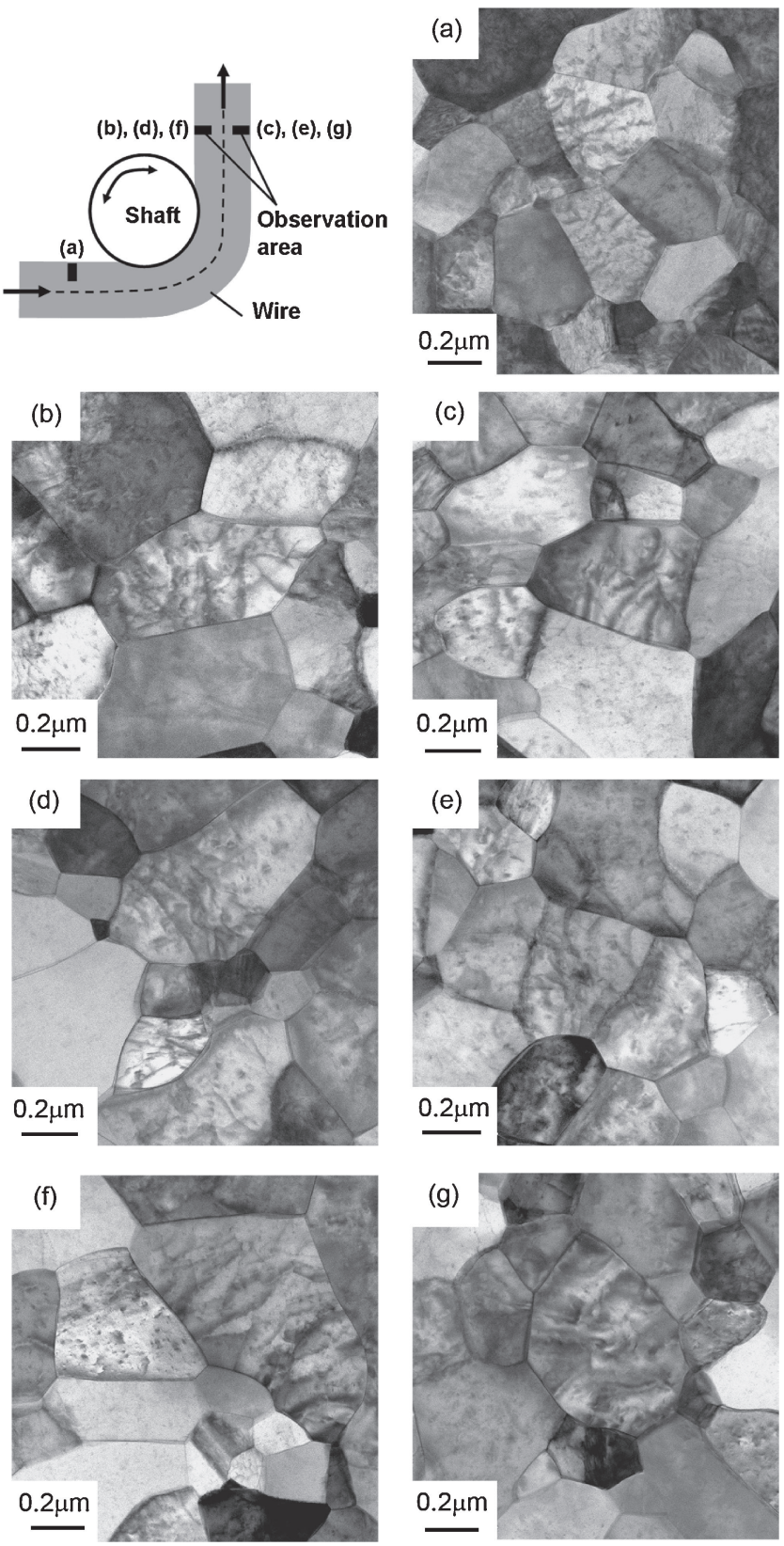

Fig. 8 STEM images of cross section of $\mathrm{Cu}-0.3$ mass $\% \mathrm{Sn}$ alloy specimens after draw bending. The micrographs in (b) and (c), (d) and (e) and (f) and (g) are obtained at velocity ratios of $-1.0,1.0$ and 3.0, respectively. The image in (a) is of the edge of the wire-drawn specimen. The images in (b), (d) and (f); and (c), (e) and (g) are of the inside and outside of the bend, respectively.

considered that the dislocations generated by the tensile stress field produced during wire drawing are relaxed by the reversed stress induced during draw bending.

\subsection{Change in microstructure during CBD process}

In this section, we discuss the change in the microstructure during the $\mathrm{CBD}$ process, particularly the change in the dislocation motion and the stress state of dislocations in ultrafine grains.

Only the plastic hysteresis in draw bending was clarified using FEM analysis by Tokutomi et al. ${ }^{14)}$ However, it is necessary to consider the plastic hysteresis because that of the CBD process has not yet been clarified. Since a large 
equivalent drawing strain of 7.2 is applied during wire drawing, it can be considered that a tensile stress field is formed in the longitudinal direction of the wire specimen. When draw bending is applied to the wire-drawn specimen, continuous reverse loading is applied to the UFGs produced during wire drawing, as shown in Fig. 10, such as on the inside and outside of the bend, where reverse loading is applied twice and once, respectively.

Next, the change in the microstructure based on the continuum mechanics in Fig. 10, particularly the change in the dislocation motion and UFGs, is considered. Since a large equivalent drawing strain of 7.2 is applied during cold wire

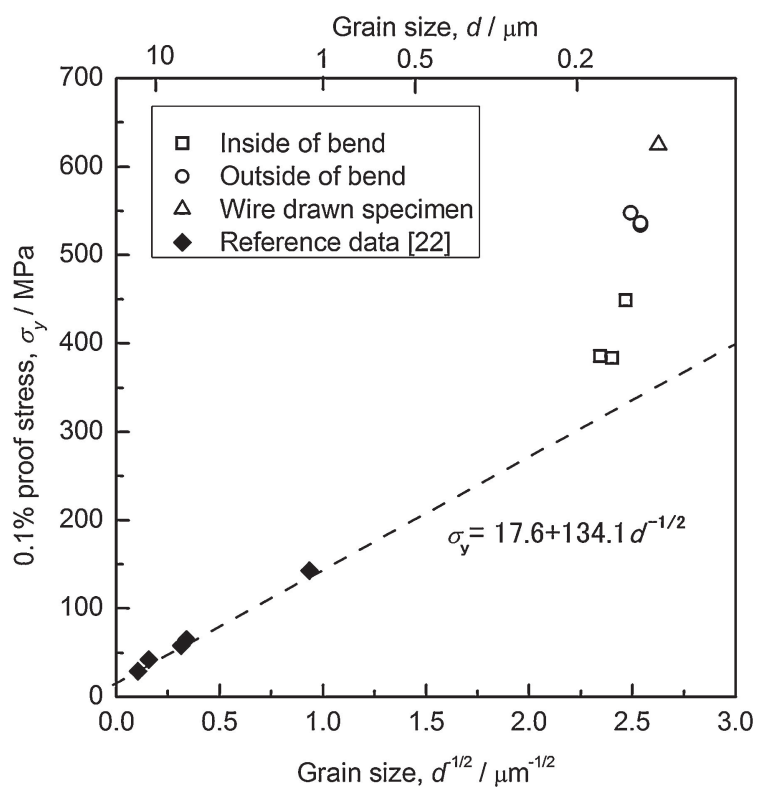

Fig. 9 Relationships between mean grain size and $0.1 \%$ proof stress on inside and outside of bend, and coarse-grain $\mathrm{Cu}-0.3$ mass $\% \mathrm{Sn}$ alloy materials cited from Aoyama and Urao. ${ }^{22)}$ drawing, it can be considered that the UFGs of the wire drawn specimen are bound very strongly to each other. Therefore, it is considered that little rotation of the UFGs occurs on the cross section and longitudinal section, as shown in Figs. 5 and 6, even if draw bending is applied to the wire-drawn specimen.

Figure 11 shows schematic illustrations of dislocation motion during the CBD process. The evolution of the microstructure induced by wire drawing was clarified by Hanazaki et al., ${ }^{10)}$ who reported that a large number of HAGBs are newly introduced in annealed grains by wire drawing. From their study, it can be deduced that tensile stress is continuously exerted in the drawing direction, which means that the dislocations in a grain have an elastic stress field in the tensile direction or in the drawing direction. Regarding the inside of the bend in the bending range, when new dislocations generated by the compressive stress of the first reverse loading encounter dislocations generated by tension during wire drawing, it can be considered that the compressive stress eases the elastic tensile stress field of the dislocations produced during wire drawing in the bending

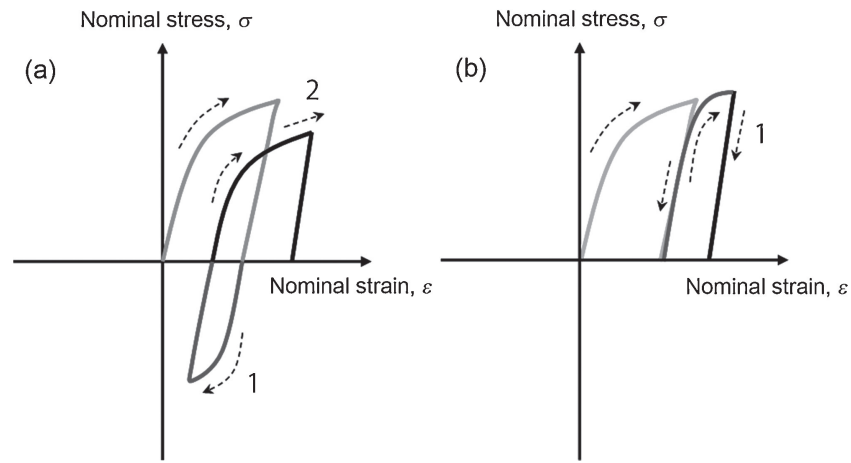

Fig. 10 Schematic illustrations of plastic hysteresis and grain deformation during CBD process.

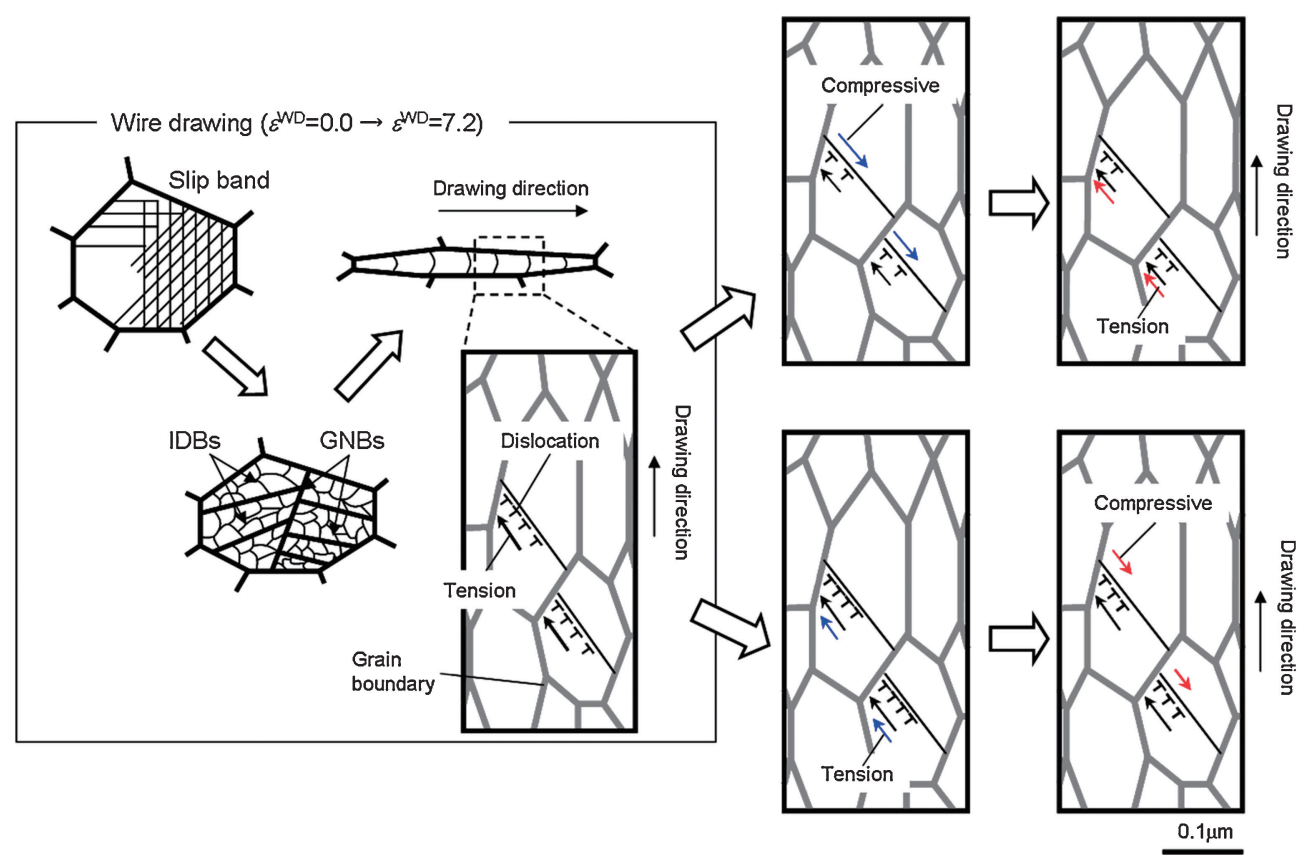

Fig. 11 Schematic illustrations showing change in dislocation motion during CBD process. 
range. In the rebending range, tensile stress is applied to the stress state of dislocations in the bending range during the second reverse loading. Consequently, the rearrangement of dislocations may be induced by this tensile stress. From the results, it can be considered that the stress field on the inside of the bend after draw bending is eased more effectively than that of the wire-drawn specimen. On the other hand, tensile stress is continuously applied in the bending range, which means that the dislocation substructure and stress state produced by wire drawing are strengthened. However, although tensile stress is continuously applied in the rebending range, the stress field of dislocations is slightly eased since the stress vector indicates the compression direction. Such structural evolution is thought to be a result of the Bauschinger effect. Brown proposed that the mechanical properties change similarly to the Bauschinger effect, which is induced by the orientation of dislocation motion. ${ }^{23)}$ It is interesting to note that the Bauschinger effect is induced by not only elastic deformation but also plastic deformation in the CBD process.

\section{Conclusions}

The changes in the mechanical properties on the inside and outside of the bend of wire specimens were clarified, and the relationship between the changes in the misorientation of substructures and in the mechanical properties was systematically investigated. The main conclusions of this study are summarized as follows.

(1) The UTS and $0.1 \%$ proof stress on the inside of the bend of the specimens were decreased by the CBD process, reaching approximately 510 and $390 \mathrm{MPa}$, respectively, at a velocity ratio of 3.0 , which are twothirds of those of the wire-drawn specimen. The UTS and $0.1 \%$ proof stress on the outside of the bend were only slightly decreased, reaching approximately 680 and $550 \mathrm{MPa}$, respectively. The inside of the bend softened more than the outside of the bend. At the same time, the total elongation on the inside of the bend increased.

(2) The wire-drawn specimen and CBD specimens exhibited a distinct texture composed of grains in the $\langle 001\rangle$ and $\langle 111\rangle$ directions at their center, which is a typical drawing texture component of f.c.c metals. The texture of grains in the $\langle 001\rangle$ and $\langle 111\rangle$ directions changed at the edge of the wire drawn specimen, and the inside and outside of the bend were found to exhibit a larger change in texture than the edge of the wiredrawn specimen. From our observation, the number fractions of HAGBs on the inside and outside of the bend were 0.723 and 0.827 at a velocity ratio of 3.0, respectively. Compared with the number fractions of HAGBs of the wire-drawn specimen, that on the inside of the bend was smaller, and that on the outside of the bend was larger.
(3) We investigated the cause of the changes in the mechanical properties, particularly the relationship between the $0.1 \%$ proof stress and the mean grain size on the inside and outside of the bend. The $0.1 \%$ proof stress decreased markedly, although the change in grain size was very small. If draw bending is performed on a wire-drawn specimen, it is considered that the dislocations produced by the tensile stress field generated during wire drawing are relaxed by the compression stress induced during draw bending, which explains the decrease in the $0.1 \%$ proof stress on the inside of the bend.

\section{Acknowledgements}

This study was financially supported by a Grant-in-Aid for Scientific Research on Innovative Areas, "Bulk Nanostructured Metals", through MEXT, Japan (Contract No. 22102005), which is gratefully appreciated. Yazaki Parts Company is also acknowledged for supplying the copper alloy rods used in this study.

\section{REFERENCES}

1) A. Azushima, R. Kopp, A. Korheonen, D. Y. Yang, F. Micari, G. D. Lahoti, P. Groche, J. Yanagimoto, N. Tsuji, A. Rosochowski and A. Yanagida: CIRP Ann. Manuf. Technol. 57 (2008) 716-735.

2) Y. Saito, H. Utsunomiya, N. Tsuji and T. Sakai: Acta Mater. 47 (1999) 579-583.

3) N. Tsuji, Y. Saito, H. Utsunomiya and S. Tanigawa: Scr. Mater. 40 (1999) 795-800.

4) N. Tsuji, R. Ueji and Y. Minamino: Scr. Mater. 47 (2002) 69-76.

5) N. Takata, S. H. Lee and N. Tsuji: Mater. Lett. 63 (2009) 1757-1760.

6) V. M. Segal: Mater. Sci. Eng. A 197 (1995) 157-164.

7) Z. Horita, M. Furukawa, T. G. Langdon and M. Nemoto: Materia Japan 37 (1998) 767-774.

8) R. Z. Valiev, A. V. Korznikov and R. R. Mulyukov: Mater. Sci. Eng. A 168 (1993) 141-148.

9) Y. Ma, M. Furukawa, Z. Horita, M. Nemoto, R. Z. Valiev and T. G. Langdon: Mater. Trans. 37 (1995) 336-339.

10) K. Hanazaki, N. Shigeiri and N. Tsuji: Mater. Sci. Eng. A 527 (2010) 5699-5707.

11) F. D. Negroni, E. G. Thomsen and S. Kobayashi: CIRP Ann. Manuf. Technol. 35 (1986) 181-183.

12) J. Yanagimoto, J. Tokutomi, K. Hanazaki and N. Tsuji: CIRP Ann. 60 (2011) 279-282.

13) J. Tokutomi, K. Hanazaki, N. Tsuji and J. Yanagimoto: Mater. Trans. 53 (2012) 116-122.

14) J. Tokutomi, K. Hanazaki, N. Tsuji and J. Yanagimoto: J. Mater. Process. Technol. 212 (2012) 2505-2513.

15) S. Kajino and M. Asakawa: Wire J. Int. 39 (2006) 64-65.

16) S. Kajino and M. Asakawa: Key Eng. Mater. 340-341 (2007) 525-530.

17) X. Huang: Scr. Mater. 38 (1998) 1679-1703.

18) E. A. Calnan and C. J. B. Clews: Philos. Mag. 41 (1950) 1085-1100.

19) Y. Wang, T. Jiao and E. Ma: Mater. Trans. 44 (2003) 1926-1934.

20) M. Niewczas, O. Engler and J. D. Embury: Acta Mater. 52 (2004) 539_ 552.

21) N. Kamikawa, X. Huang, N. Tsuji and N. Hansen: Acta Mater. 57 (2009) 4198-4208.

22) S. Aoyama and R. Urao: J. Jpn. Inst. Metals 74 (2010) 49-54.

23) L. M. Brown: Scr. Metall. 11 (1977) 127-131. 